\title{
The Research on the Path of Basic Public Service Equalization in China
}

\author{
Liu Jing ${ }^{1} \quad$ You Zhaoni \\ ${ }^{1,2}$ School of Public Administration ,Zhongnan University of Economics and Law, Wuhan,China \\ 430074
}

(E-mail:nikkii@139.com, sweetnora@sina.com)

\begin{abstract}
The Twelfth Five-Year Plan explicitly pointed out the importance of further improvement of the regional development and the equalization of basic public services. At present, China's public service still face problems such as the absence of total supply, uneven distribution and low quality. Those problems are blocking the process of our country to realize the equal access to basic public service. As the masters of the process, our government should start from its concept and scope, analyzing the problems and the reasons of our current basic public service, so as to find an effective way to realize the equal access to basic public services.
\end{abstract}

Keywords: Basic Public Service, Equalization; Government

\section{Introduction}

Equalization of basic public services is an institu-tional arrangement to build a harmonious socialist society. China is in a period of overall social transformation that include opportunities and crises, which is the critical stage to solve the problem of public service.With the construction of service-oriented government in China step by step, the basic public service equalization achieved some success, while it still faces some problems. Proceeding from the connotation of basic public service equalization, analyzing the problems in the equalization of basic public services, and thus exploring an effective way to achieve the goal of equalization of basic public services for the Chinese government ,has a very profound practical significance.

\subsection{Foreign research status}

Foreign urban-rural gap is smaller than China,Western scholars have also made a series of studies on basic public services, of which there are many theories that we can learn. Otherwise,Western developed countries had achieved practical sucess of the equalization of basic public services which we can also learn.

When Western countries are in the capitalist society,they pursued the policies of Adam Smith's economic liberalism, which discusses the country's obligations to the equitable provision of public services is the country's obligations and responsibilities. Subsequently, the capitalist world economic crisis broke out, the existence of "market failure" has brought opportunities for the rise of public services. Keynes advocated government should utilize fiscal, monetary, employment and other macroeconomic policy to achieve a comprehensive intervention in economic life, these macroeconomic policies coupled with Adam Smith's public works concept constitute generalized government public service functions. In 1954, Samuelson defined the pure public goods as"all members of the equalization of consumption goods by the Group " in his book "Pure Theory of Ppublic Expenditure" ,which reflected the idea ofequalization of public services. He listed the stability of the government functions, the efficiency of functions and equality functions to the government's public service functions that contains the equalization of public services is theidea of one of the goals of government functions. The emergence of the new public management theory, the new public service, the governance theory, the public economics in the 1990s provides a new way of thinking public service. The concept of reinventing government ,citizen standard,good governance 
and welfare also provides a useful reference to the equalization of public services.

Western developed countries formed various modes of equalization of basic public services in accordance with their own national conditions.Such as "Market oriented" model in the United States and France ,"Fair first" model in the United Kingdom and the Nordic countries,and "self-accumulation-type" mode in Singapore and Russia.These patterns in their respective countries have achieved success, the common performance includes the following aspects:(1)Policies and system guarantee. Developed countries had established and improved the legal system to protect the supply of basic public services,such as "Social Security Law "in the US,"The National Insurance Act "in the UK, and "Public Service Act" in Australia;(2)Legible division of government responsibilities. Western developed countries have a clear division of labor in the supply of basic public services for central and local government.They generally follow the benefit principle,behavioral principles and technique principles.Central government grant the power to local governments,strengthen the supply of local governments ,and local governments bear the primary responsibilities.The German Basic Law distinguish the responsibility of governments clearly, and other countries such as Britain and France are implying "Local Self-Government semi-autonomous" mode which ruled that local governments to undertake supply responsibility; (3)Financial assurance .To guarantee the local government can take the responsibility of supplying public service, Western country has made appropriate arrangements on their fiscal systems.For example,Canada used the transfer payment system to protect the equalization of basic public services ,Denmark implyed regional subsidies and equalization schemes in order to achieve balanced regional development, Australia implyed the principle of fiscal equalization and so on;(4)Social participation.As the government resources are limited, the western countries are pursuing the full realization of social participation in order to achieve the equalization of basic public services.Such as the Government operationsentrusted with the operation in UK,Municipal services outsourcing and Public-private partnership mode in US.Government, business, NGO, citizens are involved in the supply of public services ,the social and market resources are utilized fully,those are helpful to provide a more extensive and efficient public services.

\subsection{Domestic research status}

The formulation of equalization of basic public services is based on China's basic national conditions in building a service-oriented government,domestic scholars make a lot of exposition from its concept to its scope.

\subsubsection{The definition of the equalization of basic public services}

Chinese scholars described the equalization of basic public servicesfrom different perspectives.Some scholars believe that the equalization containequal balanced mean,which is not absolutely equal, but the relative fairness and equality of the opportunity and results to enjoy public service for residents.In " Equalization of Public Services Need System Support "Chang Xiuze pointed that the connotation of the equalization of basic public services should comprehend three aspects:citizens enjoy the fair opportunities and the fair principles of the basic public services,citizens have roughly equal access to the results of public services, and people's right of free choice should be respected.Some scholars defined the equalization of basic public services from the perspective of the rights of citizens.Lou Jiwei regarded it as the concrete manifestation of the people-oriented concept, which focused on citizens have the rights to enjoy the basic public service.Tang Jun also emphasized citizens have six rights in the public service area:the right to life, health,residence,education, work and asset formation in his article "Equalization of Public Services to Protect the Six Fundamental Rights ".Another part of scholars understand the equalization of basic public services from the angle of the progress.In "A Recommend on Taxation System to Build Urban and Rural Development "Jia Kang holds that the equalization of basic public services is a dynamic process that has hierarchy and stages.The initial stage target is to narrow the gap between the level of public services in regional and inter-regional area,intermediate stage target is focused on the equalization of urban and rural public services, advanced stage target is to achieve universal equalization of public services. 


\subsubsection{The scope of the equalization of basic public services}

Scholars have different views about the contents contained in the basic public service equalization.In"The Progressive Realization of the Equalization of Basic Public Services", Chang Xiuze divided equalization into four categories:equalization of the basic livelihood services,equalization of public utility services,equalization of public basic services, equalization of public safety services. In "Equalization of Public Services: Theory, Problems and Strategies "An Tifu pointed out that basic public services should refer to the pure public service that is closely related to people's livelihood, which includes The field of education, culture, employment, social security, ecological environment, public infrastructure and social security.

Scholars have discussed basic publicservice equalization from many angles. In conclusion, the basic public service equalization refers to all levels of government and its public finances should provide basic public goods and services for different residential areas, different interest groups,different economic or social classes,ensure that members of society to enjoy equal opportunities, process and results in basic public service, guarantee the relative equal of the realization of citizens' primary rights.Its scope includes Education and culture, public health, social security, infrastructure and employment services.

\section{Analysis of basic public service equalization in China}

In recent years, with the progress of service-oriented government construction, China has also made certain achievements on basic public service equalization. However,compared with Western countries, there are still a significant gap.At this stage,China's basic public services still exists the phenomenon of non-equalization, which mainly reflected in two sides:government supply unevenly and public enjoy unevenly.

\subsection{Government's uneven supply on basic public services}

In the development of market economy country, when per capita GDP by about \$1000 a well-off threshold to the period of development into well-offlevel of about $\$ 3,000$ per capita, the country'sdemand for public services is showing a trend of rapid growth. In 2008 China's per capita GDP has more than $\$ 3,000$,indicating that China is in a period of rapid expansion of public services, otherwise,basic public services provided by the Government are slightly inadequate and uneven relative to the huge demand.

\subsubsection{System of government supply uneven}

The long-standing urban-rural dual structure impeded the pace of China's basic public service equalization .Although China's emphasis on the coordinated development of urban and rural, but in fact the phenomenon that "emphasis city and contempt agricultural" still exists. Public services in rural areas is seriously lagging behind, especially the local and remote areas,they can not keep up with the pace of urban development in compulsory education, social security, infrastructure, environment and health. On compulsory education, urban ordinary primaryeducation funding, school conditions and teacher with far superior to a rural primary school.Rural areas have poor medical conditions, the health and medical resources they enjoyed are less than the city,although the new cooperative medical care system has existed,it still can not compared with the comprehensive medical insurance for urban residents. The urban-rural dual structure Led to polarization between the rich and the poor,the lack of basic public services widen this gap,so it forms a vicious cycle, and will ultimately affect thebasic public service equalization process.

\subsubsection{Government financial supply uneven}

Government's fiscal spending on basic public services is deficient.As can be seen from Table 1 , from 2006 to2010, the government for general public services expenses always maintain a level of about $12 \%$ at the total state financial expenditure .There is a substantial increase in 2007compared to 2006,but since 2007 , the general public services financial expenditure of the total actually was a declining trend.Science, education spending accounted for the proportion of the total state financial expenditure increased from $18.37 \%$ in 2006 to $24.64 \%$ in 2010 . But the growth is small and slow.Overall, for general public services and science, education, total expenditure accounted for about $30 \%$ of the entire financial expenditure.It can be seen that 
government investment inbasic public services

is obviously insufficient.

\begin{tabular}{l|lccr}
\hline Year & $\begin{array}{l}\text { Total } \\
\text { Percentage }\end{array}$ & Public service & Percentage & Science|\&education \\
\hline 2006 & 40422.73 & 4390.38 & 10.86 & 7425.98 \\
2007 & 18.37 & 8514.24 & 17.10 & 11793.96 \\
2008 & 49781.35 & & & 14992.90 \\
2009 & 23.69 & 9795.92 & 15.65 & 18569.32 \\
2010 & 62592.66 & 9164.21 & 12.01 & 22147.08 \\
& 23.95 & 9337.16 & 10.38 & \\
& 76299.93 & & & \\
& 24.33 & & & \\
& 24.674 .16 & & & \\
\hline
\end{tabular}

Table 1: The Growth of the Total State Financial Expenditureand and Components (2006-2010)

2.1.3 Uneven supply of personnel,equipment and facilities

In the provision of basic public services, the government's arrangement of personnel, equipment and facilities have differences in the quantity and quality. Overall, the basic urban public sector staff, equipment,facilities are superior to rural areas in quality and quantity.Above in the construction of infrastructure, rural areasare now being implemented the project of building the road in every village,but it still can not be compared with the urban project such as roads, waste disposal stations, water supply and drainage works.

\subsection{Citizens' uneven enjoy of the basic public service}

Basic public service equalization aimed at achieving the goal that everyone share the fruits of social development together.China is in the stage of uneven enjoying of the public service,mainly in regional disparities and urban-rural gap. The western region are enjoying far lower than the eastern and central regions, and rural areas is much lower than in urban areas in the number. In social security, $85.8 \%$ of practitioners lack of unemployment insurance, about 80 percent of the workers lack the basic pension insurance,more than 85 percent of the urban and rural residents lack of basic medical insurance. In terms of infrastructure, more than 80 percent of non-cement roads are in rural areas, more than 50 percent of administrative villages did not pass tap-water,more than $60 \%$ of the farmers lack of sanitary latrines.In public health, the city occupies $80 \%$ of the nationalhealth care resources while only $20 \%$ in rural areas.The basic public services resources are limited, together with its quality can not attract much attention, people of different regions have difference in access to basic public access.Hidden nature and unpredictable may make basic public services providers deliberately reduce the quality of service, thus exacerbating the uneven quality of basic public services.

\section{The Path Selection of Promoting Basic Public Services Equalization}

Basic public service equalization target is an arduous and complex systems engineering.It requires expressing the governments' leading force, mobilizing the social forces of all levels,establishing and improving the public system,allocating the public service system rationally,distributing the public goods and services equitably,so that of people in different groups and different regions can enjoy roughly equal public services.

\subsection{Accelerating the transformation of government functions, and building the public service-oriented government}

In the process of promoting the equalization of basic public services, the first is to clear all levels of government powers and responsibilities. The central government should undertake the responsibility of providing the basic public service, accelerate the transition to publicservice-oriented government. At the same time it is essential to reform the present central-local relations. On the one hand,clarify the respective responsibilities and establish a performance evaluation mechanism, on the other hand,give the corresponding powers of local government and reform the public finance,so as to give both power and pressure,both the duty and ability to local government public services, and encourage 
them making a difference.Establishing the basic inter-governmental public service accountability system is also essential. The implementation of the basic public services and its financial responsibility should be included into the target range of the government's public service level assessment .Moreover, enhance superior to lower-level auditing and monitoring efforts, as well as lower to higher supervision.

\subsection{Reform of the public finance system, improvement of the system of transfer payments}

Government should set the equalization of basic public services as the principles-based,increase the transfer payments to central and western regions, rural areas, minority areas, border areas, and old revolutionary base areas, in order to enhance regional capacity to provide basic public services. China's limited financial resources, and rely solely on the central disbursement is unable to achieve the equalization of basic public services across the country, and China's eastern, central and western gap is too large, the level of economic development of the eastern region is close to the level of developed countries,so we can increase the horizontal transfer between the regions when we mainly rely on the central disbursement to accelerate the coordinated development between the regions, and accelerate the pace of the equalization of public services. In addition, the state should actively adjust the structure of fiscal expenditure, regulate the allocation of public spending on services ,increase investment in basic public services when promote economic sustainable scientific development. Financial expenditure should be the people profitability rather than compete with the people. What's more,countries must strengthen thedemocratic supervision and management for public service expenditures,ensure that the public service expenditures is in accordance with established standards,prevent the funds to be withheld or misappropriated.Thus provide strong financial and institutional support for the efficient implementation of the basic public service equalization.

\subsection{Accelerating the legislative process of the equalization of basic public services}

In the process of promoting the equalization of basic public services, it's essential to improve laws and regulations system related to the basic public service equalization. The construction of basic public service legal system should be based on the Constitution on the fundamental rights of citizens,focused on the field of basic education, social security,public health, employment and reemployment,intergrat the existing laws and regulations,formulate the necessary laws and regulations, so as to build a perfect legal system of basic public system. At the same time,strengthen the substantive and procedural legislations of public finance,to form a complete system of public finance and regulations, and bring the public finances into the orbit of the rule of law. Based on existing administrative procedures and regulations, regulate the government act in the provision of basic public services,accelerate the transformation of government functions, promote the institutionalization of participation of different main participants, increase transparency,specificate the different participation mains and behavior of different main participants, establish the cooperative relations between the parties.

\subsection{Building the multiple participation supply pattern of basic public service}

Most of China's current basic public services is provided by the government,however, the governments' resources are limited,therefore, constructing the basic pattern of government-led, multi-subject participation public service supply is very necessary. As the main suppliers of the public service,government should establish effective accountability mechanisms to ensure the efficient supply of public services. Government in the provision of basic public services can not dominate the party, but should open up the channels of institutionalized participation, encourage the participation of NGO and corporate, reduce the access threshold, make full use of market and social resources, foster the awareness of civil rights, broaden the channels for citizen participation, guide the citizens' active and orderly participation, express their demands,finally establish a coordinated social network between government departments, market, civil society organizations and citizens based on the trust and mutual benefit. Then create a new public policy decision-making mechanism, through public participation, multiple mechanisms of expression of interest and system innovation, 
to achieve the balance of values and interests, and enhance the transparency of public services, to promote the public interest to maximize.

\section{4.conculsion}

Basic public service equalization is a difficult engineering, Its full realization is of a long-term dynamic process. Government should play its leading role in this process, with a corresponding adjustment in the construction of legal, institutional arrangements and financial supply, so as to achieve a comprehensive and coordinated development of the country as soon as possible.

\section{References}

[1]Liao Wenjian. Experience and enlightenment of the Western Developed Countries's Basic Public Service Equalization Path Selection[J].Chines Public Administration, 2011 (03) (In Chinese)

[2]Chang Xiuze. Equalization of Public Services Need System Support[J].Outlook Weekly, 2007 (07)

[3]Tang Jun. Equalization of Public Services to Protect the Six Fundamental Rights[J]. Current Affairs Report,2006(06). (In Chinese)

[4]Jia Kang. A Recommend on Taxation System to Build Urban and Rural Development[J].Economic Review,2011(01). (In Chinese)

[5] Chang Xiuze. The Progressive Realization of the Equalization of Basic Public Services[N]. People's Daily,2008-01-31. (In Chinese)

[6]An Tifu,Ren Qiang. Equalization of Public Services: Theory, Problems and Strategies $[\mathrm{J}]$. Finance and Trade Economics,2009(8) (In Chinese)

[7]National Bureau of Statistics of China.China Statistical Yearbook 2011[M].Beijing:Chinese Statistical Press,2011. (In Chinese)

[8]Jing Min.The Path Selection on Advancing Basic Public Services Equalization.[J].Tribune of Study,2008(10). (In Chinese) 